\title{
ЧЕРТЫ ЛИЧНОСТИ И УСТАНОВКИ НА ЧЕРТЫ: СВЯЗИ И РАЗЛИЧИЯ
}

\begin{abstract}
А.М. МИШКЕВИЧ
${ }^{a}$ Пермский государственный национальный исследовательский университет, 614990, Россия, Пермь, ул. Букарева, Ә. 15

\section{Резюме}

В рамках пятифакторной теории личности предполагается, что врожденные черты личности влияют на объективную биографию через характерные адаптации (McCrae, Costa, 2013). Установки на черты являются рефлексивной разновидностью характерных адаптаций. Установки на черты определяются как биполярные (положительные/отрицательные) социальные установки индивида на психологический конструкт, хранящиеся в семантической памяти без прямой отсылки к какому-либо индивиду, включая самого респондента (Shchebetenko, 2014). Целью данного исследования было изучение валидности конструкта установок на черты. В результате эмпирического исследования с общей выборкой 1226 человек была получена структура установок на черты, в целом повторяющая пятифакторную структуру черт личности. Все установки коррелировали между собой, но при этом размер корреляций не превышал значения $\mathrm{r}=0.48$, т.е. установки на разные черты являются разными, хотя и связанными между собой конструктами. Были получены сильные корреляции между открытостью, доброжелательностью, экстраверсией и соответствующими установками; умеренные корреляции между добросовестностью и установкой на нее; слабая корреляция между нейротизмом и установкой на него. Факторный анализ показал, что установки на черты образуют один общий фактор. Структурное моделирование продемонстрировало, что теоретические предположения о влиянии черт личности, образующих факторы Стабильности/Пластичности, на единый фактор, образованный установками на черты в целом, соответствуют эмпирическим данным. Перспективы изучения конструкта установок на черты связаны с исследованиями данного феномена на другой возрастной группе, а также с изучением установок на черты в разных культурах.
\end{abstract}

Ключевые слова: пятифакторная теория, личность, характерные адаптации, установки на черты, черты личности.

\section{Черты личности и установки на черты: связи и различия}

Одним из ключевых вопросов психологии на протяжении всей ее истории остается вопрос о структуре личности. В рамках теории Большой пятерки

Исследование выполнено при финансовой поддержке РФФИ в рамках научного проекта № 18-313-00034. 
(Big Five) предполагается, что особенности личности можно определить, исходя из анализа пяти черт: экстраверсии, добросовестности, доброжелательности, нейротизма и открытости опыту. Одной из самых заметных теорий в рамках пятифакторной модели является одноименная, пятифакторная теория (Five Factor Theory - FFT) Р. Маккре и П. Косты (McCrae, Costa, 2013). Ее авторы предполагают, что черты личности, являясь полностью врожденными, образуют так называемые базовые тенденции (basic tendencies). При этом на «объективную биографию» (objective biography), включающую среди прочего и поведение индивида, базовые тенденции влияют опосредованно, через приобретенные качества, именуемые «характерными адаптациями» (characteristic adaptations). Характерные адаптации, в свою очередь, включают широкий спектр различных феноменов: навыков, ценностей, установок. По сути, Р. Маккре и П. Коста не конкретизируют конструкт характерных адаптаций, за счет чего он становится неопределенным и одновременно достаточно универсальным.

Попытки определить и изучить характерные адаптации делают несколько авторов (Щебетенко, 2015; DeYoung, 2015; McAdams, Pals, 2006). В частности, С.А. Щебетенко (2015) считает, что особое значение для поведения личности может иметь рефлексия индивида о чертах.

Теоретически черту личности можно понимать как математическое ожидание всех случаев поведения в жизни данного индивида (Щебетенко, личная беседа). При таком определении черта личности эмпирически неизмерима. Однако ее можно оценить тем или иным способом. Самоотчетные вопросники личности являются наиболее адекватным способом оценки черты. В то же время такая ситуация дает основания рассматривать самоотчетно измеренную черту не только как оценку объективной черты, но и как метакогнитивный продукт, мнение индивида о своей личности со всеми вытекающими ограничениями и спецификой. В частности, это означает, что индивид может рефлексировать идею личности не только под углом зрения своего Я и самоидентичности, но и с каких-то иных позиций. Множество этих позиций и образует особый вид характерных адаптаций - рефлексивных (PXA Щебетенко, 2015).

Особый взгляд на черты личности может формироваться с позиции оценки. Этот взгляд характеризует форму РХА, известную как установки на черты (Shchebetenko, 2014). Формально они определяются как биполярные (положительные/отрицательные) социальные установки индивида на психологический конструкт. Установки хранятся в семантической памяти без прямой отсылки к какому-либо индивиду, включая самого респондента (Ibid.). Например, человек может считать доброжелательность положительным качеством, а экстраверсию - отрицательным; при этом себя он вполне может оценивать как враждебного и интровертированного человека.

Прагматическое значение установок на черты заключается в том, что этот конструкт не только расширяет понимание личности, но и предположительно опосредует влияние черт личности на поведение человека. Кроме того, он может вносить и уникальный вклад в объяснение объективно наблюдаемого 
поведения в тех случаях, когда связь с самоотчетной чертой оказывается статистически незначимой. Эти предположения предварительно подтверждаются рядом исследований (Балабина, 2015; Щебетенко, Тютикова, 2015; и др.).

Целью данного исследования являлось изучение валидности конструкта установок на черты. Соответствует ли структура установок на черты структуре черт? Будут ли установки на черты коррелировать с собственно чертами? Будет ли подтверждена согласованность общей структуры черт и установок на черты с эмпирическими данными? До сих пор эти вопросы были изучены в единственном исследовании (Shchebetenko, 2014). Однако в нем эти проблемы изучались апостериорно, что заметно ослабляет их достоверность. При интерпретации результатов нашего исследования мы будем, в частности, ориентироваться на эти данные, т.е. наше исследование носит в этом смысле конфирматорный характер (McBee, Field, 2017).

\section{Участники}

В исследовании приняли участие 1226 человек, студенты пермских вузов, среди них 389 мужчин (31.7\%). Возраст испытуемых варьировался от 16 до 25 лет $(\mathrm{M}=19.22 ; \mathrm{SD}=1.08)$.

\section{Методики}

Для диагностики черт личности использовалась русскоязычная версия (Shchebetenko, 2014) «Вопросника Большой пятерки» (Big Five Inventory; BFI) (John et al., 2008). Шкалы методики продемонстрировали хороший уровень внутренней согласованности: $\alpha=0.83,0.71,0.80,0.82,0.80$ для экстраверсии, доброжелательности, добросовестности, нейротизма и открытости соответственно. Установки на черты измерялись соответствующей модификацией BFI (ABFI) (Shchebetenko, 2014).

\section{Результаты}

\section{Факторизащия пунктов и внутренняя согласованность}

Шкалы опросника ABFI продемонстрировали приемлемые показатели внутренней согласованности: $\alpha=0.66,0.71,0.71,0.70,0.76$ для установок на экстраверсию, доброжелательность, добросовестность, нейротизм и открытость соответственно.

Полученная факторная структура в целом повторяет пятифакторную структуру черт личности (таблица 1).

Наибольшее количество пунктов, показавших нагрузку менее 0.30 на основной фактор, было обнаружено для установок на доброжелательность (4 пункта) и на нейротизм (3 пункта). При этом внутренняя согласованность данных пунктов является достаточно высокой ( $\alpha=0.71$ и 0.70 соответственно). Два пункта имеют нагрузку меньше 0.30 для установки на добросовестность. 
Факторный анализ пунктов модификации Big Five Inventory, измеряющей установки на черты

\begin{tabular}{|c|c|c|c|c|c|c|}
\hline \multirow{2}{*}{\multicolumn{2}{|c|}{ Пункты }} & \multicolumn{5}{|c|}{ Компоненты } \\
\hline & & \multirow{2}{*}{$\begin{array}{c}1 \\
0.02\end{array}$} & \multirow{2}{*}{$\begin{array}{c}2 \\
-0.03\end{array}$} & \multirow{2}{*}{$\begin{array}{c}3 \\
0.14\end{array}$} & \multirow{2}{*}{$\begin{array}{c}4 \\
0.69\end{array}$} & \multirow{2}{*}{$\begin{array}{c}5 \\
0.02\end{array}$} \\
\hline 1 & разговорчивость & & & & & \\
\hline 6 & сдержанность (р) & 0.07 & 0.03 & -0.14 & 0.27 & -0.36 \\
\hline 11 & энергичность & 0.21 & 0.06 & 0.08 & 0.49 & 0.32 \\
\hline 16 & заражение энтузиазмом окружающих & 0.40 & 0.09 & 0.16 & 0.31 & 0.29 \\
\hline 21 & молчаливость (р) & -0.01 & 0.18 & -0.12 & 0.65 & -0.15 \\
\hline 26 & уверенность в себе & 0.12 & 0.02 & -0.04 & 0.44 & 0.32 \\
\hline 31 & застенчивость (р) & -0.05 & 0.22 & -0.42 & 0.40 & 0.03 \\
\hline 36 & общительность & 0.11 & 0.05 & 0.17 & 0.72 & 0.17 \\
\hline 2 & склонность спорить и видеть в других недостатки (р) & -0.01 & 0.59 & 0.27 & -0.19 & -0.05 \\
\hline 7 & бескорыстность, готовность помочь & 0.12 & 0.12 & 0.61 & 0.07 & 0.19 \\
\hline 12 & склонность затевать споры с другими людьми (р) & -0.08 & 0.56 & 0.27 & -0.01 & -0.05 \\
\hline 17 & склонность прощать других & 0.12 & 0.10 & 0.62 & 0.11 & 0.01 \\
\hline 22 & доверие к окружающим & 0.08 & 0.03 & 0.61 & 0.26 & -0.05 \\
\hline 27 & холодность и надменность (р) & 0.11 & 0.51 & 0.30 & 0.12 & -0.09 \\
\hline 32 & тактичность и доброта почти ко всем & 0.20 & 0.13 & 0.63 & 0.05 & 0.13 \\
\hline 37 & грубость (р) & 0.17 & 0.60 & 0.25 & 0.08 & 0.14 \\
\hline 42 & склонность к сотрудничеству с другими людьми & 0.18 & 0.05 & 0.22 & 0.51 & 0.21 \\
\hline 3 & склонность работать основательно & 0.05 & 0.12 & 0.07 & 0.08 & 0.55 \\
\hline 8 & небрежность (р) & -0.06 & 0.41 & -0.07 & 0.18 & 0.31 \\
\hline 13 & надежность в работе & 0.01 & 0.21 & 0.12 & 0.13 & 0.55 \\
\hline 18 & неорганизованность (р) & -0.02 & 0.38 & -0.06 & 0.13 & 0.40 \\
\hline 23 & ленивость (р) & 0.03 & 0.45 & -0.10 & 0.20 & 0.29 \\
\hline 28 & склонность доводить начатое дело до конца & 0.13 & 0.17 & 0.08 & 0.21 & 0.56 \\
\hline 33 & эффективность в работе & 0.15 & 0.10 & 0.13 & 0.10 & 0.59 \\
\hline 38 & следование своему плану & 0.07 & 0.00 & 0.03 & 0.28 & 0.43 \\
\hline 43 & легкая отвлекаемость от чего-либо (р) & 0.03 & 0.20 & -0.18 & -0.10 & 0.18 \\
\hline 4 & подавленность, депрессивность & -0.02 & -0.40 & 0.06 & -0.33 & -0.18 \\
\hline 9 & расслабленность, хорошая регуляция стресса (р) & -0.19 & -0.01 & -0.03 & 0.03 & -0.47 \\
\hline 14 & напряженность & -0.16 & -0.49 & 0.14 & -0.17 & -0.16 \\
\hline 19 & беспокойство & -0.10 & -0.42 & 0.30 & -0.04 & -0.08 \\
\hline
\end{tabular}


Таблица 1 (окончание)

\begin{tabular}{|c|c|c|c|c|c|c|}
\hline \multirow{2}{*}{\multicolumn{2}{|c|}{ Пункты }} & \multicolumn{5}{|c|}{ Компоненты } \\
\hline & & \multirow{2}{*}{$\begin{array}{c}1 \\
-0.22\end{array}$} & \multirow{2}{*}{$\begin{array}{c}2 \\
-0.10\end{array}$} & \multirow{2}{*}{$\begin{array}{c}3 \\
0.05\end{array}$} & \multirow{2}{*}{$\begin{array}{c}4 \\
0.03\end{array}$} & \multirow{2}{*}{$\begin{array}{c}5 \\
-0.47\end{array}$} \\
\hline 24 & $\begin{array}{l}\text { эмоциональная устойчивость, неподатливость } \\
\text { расстройству (р) }\end{array}$ & & & & & \\
\hline 29 & $\begin{array}{l}\text { подверженность смене настроения, } \\
\text { периодическая раздражительность }\end{array}$ & 0.00 & -0.53 & 0.09 & -0.12 & -0.22 \\
\hline 34 & спокойствие в напряженных ситуациях (р) & -0.14 & -0.05 & -0.02 & -0.02 & -0.61 \\
\hline 39 & склонность начинать нервничать & -0.12 & -0.49 & 0.12 & -0.11 & -0.26 \\
\hline 5 & $\begin{array}{l}\text { оригинальность и творческость, переполненность } \\
\text { новыми идеями }\end{array}$ & 0.51 & 0.04 & 0.07 & 0.18 & 0.30 \\
\hline 10 & интерес к массе разнообразных вещей & 0.47 & -0.06 & 0.15 & 0.21 & 0.25 \\
\hline 15 & глубина мышления, остроумие & 0.47 & 0.03 & -0.09 & 0.05 & 0.38 \\
\hline 20 & богатое воображение & 0.55 & -0.04 & 0.07 & 0.16 & 0.20 \\
\hline 25 & изобретательность & 0.44 & 0.02 & 0.01 & 0.06 & 0.42 \\
\hline 30 & $\begin{array}{l}\text { высокая оценка искусства и эстетических } \\
\text { переживаний }\end{array}$ & 0.71 & 0.03 & 0.18 & 0.01 & -0.01 \\
\hline 35 & предпочтение рутинной работы (р) & 0.29 & 0.15 & -0.29 & 0.07 & -0.15 \\
\hline 40 & любовь к размышлениям, «развивать идеи» & 0.56 & 0.03 & 0.08 & 0.13 & 0.28 \\
\hline 41 & отсутствие интереса к искусству (р) & 0.61 & 0.18 & 0.04 & 0.02 & -0.14 \\
\hline & ДОд, \% & 8.09 & 7.43 & 5.87 & 7.13 & 9.25 \\
\hline
\end{tabular}

Примечание. Методом главных компонент (вращение Варимакс) зафиксировано пять компонент. Перед содержанием пункта приводится его порядковый номер в опроснике. ДОД - доля объясненной дисперсии, p - реверсивный пункт. Полужирным шрифтом выделены факторные нагрузки пунктов, входящих в соответствующую шкалу вопросника Большой пятерки. Курсивом выделены факторные нагрузки пунктов на другие компоненты, превышающие 0.30 . Компонента 1 - установка на открытость, компонента 2 - установка на нейротизм, компонента 3 - установка на доброжелательность, компонента 4 - установка на экстраверсию, компонента 5 - установка на добросовестность. $\mathrm{N}=1226$.

По одному пункту с нагрузкой меньше 0.30 было получено для установок на экстраверсию и открытость. В целом данные пять факторов объяснили порядка $37.77 \%$ общей дисперсии, что свидетельствует о наличии значительных остаточных корреляций.

Установки на черты были связаны между собой в диапазоне от слабых до умеренных корреляций (таблица 2).

В целом установки на все пять черт личности значимо коррелировали между собой. При этом размер корреляций не превышал $r=0.48$. Факторный анализ шкал ABFI показал наличие одного общего фактора, объяснившего порядка 46.34\% общей дисперсии (таблица 3). 
Корреляции установок на черты между собой

\begin{tabular}{|c|c|c|c|c|}
\hline Установки на черты & Уст_Дж & Уст_Дс & Уст_H & Уст_O \\
\hline Уст_Э & $0.26^{* * *}$ & $0.35^{* * *}$ & $-0.34^{* * *}$ & $0.31^{* * *}$ \\
\hline Уст_Дж & & $0.30 * * *$ & $-0.30 * * *$ & $0.27^{* * *}$ \\
\hline Уст_Дс & & & $-0.48 * * *$ & $0.32^{* * *}$ \\
\hline $\mathrm{Y}_{\mathrm{CT}} \_\mathrm{H}$ & & & & $-0.33^{* * *}$ \\
\hline
\end{tabular}

Примечание. В таблице приведены корреляции Пирсона. Уст_Э - установка на экстраверсию, Уст_Дж - установка на доброжелательность, Уст_Дс - установка на добросовестность, Уст_H - установка на нейротизм, Уст_О - установка на открытость. ${ }^{* * *} p \leqslant 0.001 . \mathrm{N}=1226$.

Таблица 3

Факторный анализ шкал модификации Big Five Inventory, измеряющей установки на черты

\begin{tabular}{|l|c|}
\hline \multicolumn{1}{|c|}{ Установки на черты } & Компонента 1 \\
\hline Установка на экстраверсию & $\mathbf{0 . 6 6}$ \\
\hline Установка на доброжелательность & $\mathbf{0 . 6 0}$ \\
\hline Установка на добросовестность & $\mathbf{0 . 7 4}$ \\
\hline Установка на нейротизм & $\mathbf{- 0 . 7 4}$ \\
\hline Установка на открытость & $\mathbf{0 . 6 5}$ \\
\hline ДОд, \% & 46.34 \\
\hline
\end{tabular}

Примечание. Метод главных компонент, вращение Варимакс. ДОД - доля объясненной дисперсии. Полужирным шрифтом выделены факторные нагрузки, превышающие $0.30 . \mathrm{N}=1226$.

Таким образом, можно сказать, что, несмотря на сильную взаимосвязь между установками на разные черты личности, они все различаются между собой.

\section{Сопряженности черт и установок на черть}

Далее мы оценили взаимосвязь черт личности и установок на черты (таблица 4).

Были получены сильные корреляции между экстраверсией, доброжелательностью, открытостью и соответствующими установками. Между добросовестностью и установкой на добросовестность обнаружена умеренная корреляция. Наконец, нейротизм и установка на нейротизм коррелировали слабо. Этот паттерн взаимосвязей полностью согласуется с ранее полученными результатами (Shchebetenko, 2014).

\section{Общая структура черт Большой пятерки и установок на чертьь}

Для изучения взаимосвязи черт личности и установок на черты мы построили модель, представленную на рисунке 1. Мы исходили из теоретических 
Таблица 4

Корреляции установок на черты и черт личности

\begin{tabular}{|l|c|c|c|c|c|}
\hline & Уст_Э & Уст_Дж & Уст_Дс & Уст_H & Уст_о \\
\hline Экстраверсия & $0.41^{* * *}$ & $0.07^{* *}$ & $0.09^{* *}$ & $-0.08^{* *}$ & $0.11^{* * *}$ \\
\hline Доброжелательность & $0.19^{* * *}$ & $0.50^{* * *}$ & $0.12^{* * *}$ & $-0.09^{* *}$ & $0.12^{* * *}$ \\
\hline Добросовестность & $0.14^{* * *}$ & $0.13^{* * *}$ & $0.28^{* * *}$ & $-0.07^{*}$ & -0.02 \\
\hline Нейротизм & $-0.07^{*}$ & 0.02 & 0.03 & $0.13^{* * *}$ & 0.04 \\
\hline Открытость & $0.13^{* * *}$ & $0.08^{* *}$ & $0.10^{* * *}$ & $-0.09^{* *}$ & $0.52^{* * *}$ \\
\hline
\end{tabular}

$* p<0.05, * * p<0.01, * * * p<0.001$.

Примечание. В таблице приведены корреляции Пирсона. Уст_Э - установка на экстраверсию, Уст_Дж - установка на доброжелательность, Уст_Дс - установка на добросовестность, Уст_H - установка на нейротизм, Уст_О - установка на открытость. N = 1226 .

Рисунок 1

\section{Структурная модель черт личности как предиктора установок на черты $(\mathrm{N}=1226)$}

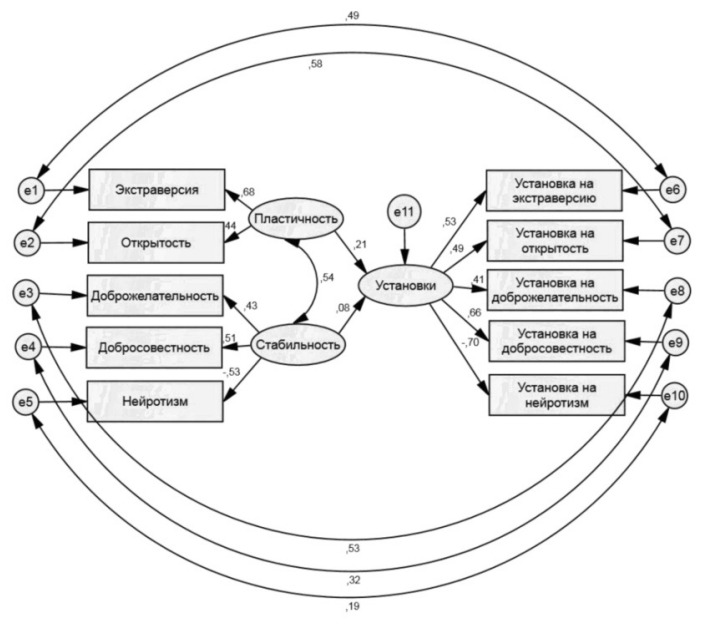

предположений о наличии в структуре личности двух предельно общих факторов: $\alpha$ (включающий добросовестность, эмоциональную стабильность и доброжелательность) и $\beta$ (включающий открытость опыту и экстраверсию) (DeYoung, 2015). Исходя из эксплораторного факторного анализа, мы предположили, что установки на черты будут образовывать один общий фактор. Поскольку в рамках пятифакторной модели предполагается, что врожденные черты личности влияют на приобретенные характерные адаптации, в нашей модели влияние черт на установки является односторонним. Также мы учли наличие корреляций между чертами и установками на соответствующие черты, в связи с этим в модель была включена ковариация остатков черт с остатками установок на соответствующие черты. 
Данная модель имела индексы, либо указывающие на ее пригодность, либо приближающиеся к таковым: $\chi^{2}(27)=171.67$, CFI $=0.946$, TLI $=0.911$, $\mathrm{RMSEA}=0.066, \mathrm{BIC}=370.79$. Таким образом, теоретические предположения в целом подтверждались эмпирическими данными. Интересно, что в данном исследовании был воспроизведен полученный ранее статистически незначимый эффект (Shchebetenko, 2014) черт Стабильности на установки на черты $(p=0.222)$.

Поскольку выборка являлась несбалансированной по полу, полученная структура была проверена с помощью мультигруппового факторного анализа на группах юношей и девушек (таблица 5). В результате было показано, что данная модель обладает конфигурационной и метрической инвариантностью. Показатели скалярной инвариантности оказались недостаточными (Chen, 2007): разница в $\chi^{2}$ между метрической и скалярной моделями была статистически значимой, $\chi^{2}(7)=181.807, p<0.000$, а разница в значениях CFI превышала 0.01 .

Таким образом, для юношей и девушек обнаружено соответствие факторной модели, а именно эквивалентность по количеству факторов и по взаимосвязям между ними (конфигурационная инвариантность). Также подтверждено равенство нагрузок наблюдаемых переменных на латентные факторы для разных групп (метрическая инвариантность). Эти результаты свидетельствуют в пользу структурного соответствия теста для мужчин и женщин, что делает осмысленным дальнейший анализ половых различий. В то же время при введении в модель ограничения на эквивалентность интерсептов показатели пригодности значительно ухудшились ( $\triangle \mathrm{CFI}>0.01)$, что свидетельствует о половых различиях в указанных параметрах (отсутствие скалярной инвариантности).

\section{Обсуждение}

Целью данной работы была проверка валидности конструкта установок на черты. Пятифакторная структура установок на черты объяснила в совокупности

Таблица 5

Показатели соответствия мультигрупповых моделей, основанных на совмещении девушек и юношей

\begin{tabular}{|l|c|c|c|c|c|c|c|}
\hline \multicolumn{1}{|c|}{ Инвариантность } & $\boldsymbol{\chi}^{2}$ & df & RMSEA & $\Delta$ RMSEA & CFI & $\Delta$ CFI & TLI \\
\hline Конфигурационная & 167.670 & 54 & 0.041 & & 0.958 & & 0.929 \\
\hline Метрическая & 180.391 & 61 & 0.040 & 0.001 & 0.956 & 0.002 & 0.934 \\
\hline Скалярная & 362.198 & 68 & 0.059 & -0.019 & 0.890 & 0.065 & 0.855 \\
\hline
\end{tabular}

Примечание. $\chi^{2}$ - значение статистики хи-квадрат; $\mathrm{df}$ - степени свободы; RMSEA - корень среднеквадратичной ошибки аппроксимации; CFI - сравнительный индекс соответствия; TLI индекс Такера-Льюиса. Группы юношей ( $\mathrm{n}=389)$ и девушек ( $\mathrm{n}=837)$. 
порядка 37.77\% общей дисперсии, при этом некоторые пункты были сильнее нагружены на «чужие» факторы. Данные результаты согласуются с полученными ранее (Shchebetenko, 2014) и свидетельствуют о значительных остаточных корреляциях. В частности, об особой, пока неизученной структуре установок на черты, отличающейся от пятифакторной структуры черт.

В этой связи показателен результат факторного анализа шкал методики ABFI. Так же, как и в предыдущем исследовании, был получен один общий фактор, объяснивший порядка 46.34\% дисперсии. Такая внутренняя структура установок отличается от структуры черт личности, которые обычно (DeYoung, 2015) образуют два фактора (см., например: Shchebetenko, 2014; Мишкевич, Щебетенко, 2017), т.е. в случае с установками на черты можно скорее говорить о наличии довольно устойчивых образов «хорошего/плохого» индивида. Хотя большая доля необъясненной дисперсии все-таки свидетельствует о значительной индивидуальной вариативности в данных образах.

Тем не менее все пять факторов установок на черты продемонстрировали приемлемые показатели внутренней согласованности (от 0.66 до 0.76), а корреляции между разными установками не превышали значения $\mathrm{r}=0.48$. Это говорит о том, что, хотя установки на разные черты сильно связаны между собой, это все же разные конструкты.

Взаимосвязи черт и соответствующих установок различаются: между экстраверсией, доброжелательностью, открытостью и соответствующими им установками обнаружены сильные корреляции, т.е. участники были склонны оценивать эти черты по-разному в зависимости от того, насколько у них самих они были выражены. Напротив, корреляция между добросовестностью и установкой на нее была умеренной, а между нейротизмом и установкой на него оказалась слабой. Вероятно, это объясняется общей положительной (для добросовестности) и отрицательной (для нейротизма) оценкой данных черт. Об этом свидетельствуют и показатели асимметрии (для добросовестности 1.204; для нейротизма 0.734) и эксцесса (добросовестность - 3.01; нейротизм - 1.81), имеющие существенные отклонения от нормального распределения. Иными словами, установки на нейротизм и добросовестность сравнительно слабо зависят от выраженности этих черт у индивида. Эти результаты полностью согласуются с полученными ранее (Shchebetenko, 2014).

Важным результатом является подтверждение пригодности теоретической модели взаимосвязи черт личности и установок на черты. Данная модель согласуется с теоретическими предположениями о наличии факторов Пластичности/Стабильности в структуре черт (DeYoung, 2015) и с пятифакторной теорией, предполагающей влияние черт личности на характерные адаптации (в нашем случае на установки на черты - McCrae, Costa, 2013). Была подтверждена конфигурационная и метрическая инвариантность модели взаимосвязи черт и установок на черты для девушек и юношей. Это свидетельствует о половом соответствии структуры взаимосвязей черт и установок на черты. Отсутствие скалярной инвариантности, которое также было обнаружено, свидетельствует о том, что мужчины и женщины различаются между собой по собственным значениям черт и установок на черты. Этот результат согласуется 
с многочисленными данными по половым различиям в чертах личности (De Bolle et al., 2015; Shchebetenko, 2017; и др.).

Итак, в данном исследовании нам удалось реплицировать структуру установок на черты и структуру личности, полученную в одном ранее опубликованном исследовании (Shchebetenko, 2014). Кроме этого, была продемонстрирована дискриминантная валидность конструкта установок на черты в сравнении с собственно чертами. Вместе с тем выборку данного исследования составили студенты, что является серьезным ограничением. Вероятно, следующим шагом в изучении социальных установок на черты должно стать исследование данного феномена на более репрезентативной выборке и кросскультурное исследование установок на черты.

\section{Литература}

Балабина, А. Д. (2015). Рефлексивные адаптации характера и социометрический статус. Вестник Пермского университета. Философия. Психология. Социология, 22(2), 55-64.

Мишкевич, А. М., Щебетенко, С. А. (2017). Психометрика русскоязычной версии Big Five Inventory: новые свидетельства. В кн. А. Л. Журавлев, В. А. Кольцова (ред.), Фундаментальные и прикладные исследования современной психологии: результаты и перспективы развития (с. 771-776). М.: Институт психологии РАН.

Щебетенко, С. А. (2015). Рефлексивные адаптации характера в пятифакторной теории личности. Психологический журнал, 36(6), 55-65.

Щебетенко, С. А., Тютикова, Е. А. (2015). «Картина хороша, потому что хороша открытость опыту»: опосредующая роль установок на черты личности в индивидуальных различиях отношения к живописи. Психология. Журнал Высшей школы экономики, 12(4), 122-141.

Ссылки на зарубежные источники см. в разделе References после англоязычног блока.

Мишкевич Арина Михайловна - старший преподаватель, кафедра психологии развития, Пермский государственный национальный исследовательский университет.

Сфера научных интересов: психология личности, социальные установки.

Контакты: ArinaMishkevich@ya.ru 


\title{
Personality Traits and Attitudes toward Traits: Relationships and Differences
}

\author{
A.M. Mishkevich ${ }^{\mathrm{a}}$ \\ ${ }^{a}$ Perm State University, 15 Bukireva Str., Perm, 614990, Russian Federation
}

\begin{abstract}
According to the Five Factor Theory (McCrae \& Costa, 2013), innate personality traits affect an objective biography after a characteristic adaptation. Attitudes toward traits are a reflexive kind of characteristic adaptations. Attitudes toward traits represent bipolar (positive vs. negative) evaluations of a psychological construct, stored in semantic memory, without reference to a particular person (Shchebetenko, 2014). The aim of this research is to study the validity of attitudes toward traits. As a result of an empirical study with a total sample of 1226 people, the structure of attitudes toward traits was obtained, generally repeating the five-factor structure of personality traits. All attitudes correlated with each other, correlation coefficient did not exceed $\mathrm{r}=.48$, i.e., attitudes towards different traits are different, although related, phenomena. Strong correlations between openness, agreeableness, extraversion and the corresponding attitudes were discovered; moderate correlations between conscientiousness and the attitude to it were obtained; a weak correlation between neuroticism and the attitude toward it was found. Factor analysis showed that attitudes toward traits form one common factor. Structural modeling has demonstrated that theoretical hypotheses about the influence of personality traits, forming factors of Stability/Plasticity, on a single factor, formed by the attitudes toward traits, correspond to empirical data in general. The prospects of research are studies in another age group, and cross-cultural studies.
\end{abstract}

Keywords: Five Factor Theory; personality; characteristic adaptations; attitudes toward traits; socially desirable; personality traits.

\section{References}

Balabina, A. D. (2015). Reflexive characteristic adaptations and sociometric status. Perm University Herald. Series "Philosophy. Psychology. Sociology", 22(2), 55-64. (in Russian)

Chen, F. F. (2007). Sensitivity of goodness of fit indexes to lack of measurement invariance. Structural Equation Modeling: A Multidisciplinary Journal, 14(3), 464-504.

De Bolle, M., De Fruyt, F., McCrae, R. R., Löckenhoff, C. E., Costa, P. T., Aguilar-Vafaie, M. E., ... Terracciano, A. (2015). The emergence of sex differences in personality traits in early adolescence: A cross-sectional, cross-cultural study. Journal of Personality and Social Psychology, 108(1), 171-185.

DeYoung, C. G. (2015). Cybernetic big five theory. Journal of Research in Personality, 56, 33-58. doi:10.1016/j.jrp.2014.07.004

John, O. P., Naumann, L. P., \& Soto, C. J. (2008). Paradigm shift to the integrative Big Five trait taxonomy: History, measurement, and conceptual issues. In O. P. John, R. W. Robins, \& L. A. Pervin (Eds.), Handbook of personality: Theory and research (pp. 114-158). New York: Guilford Press. 
McAdams, D. P., \& Pals, J. L. (2006). A new Big Five: fundamental principles for an integrative science of personality. American Psychologist, 61(3), 204-217. doi:10.1037/0003-066X.61.3.204

McBee, M., \& Field, S. (2017). Confirmatory study design, data analysis, and results that matter. In M. C. Makel \& J. A. Plucker (Eds.), Toward a more perfect psychology: Improving trust, accuracy, and transparency in research (pp. 59-78). Washington, DC: American Psychological Association. doi:10.1037/0000033-004

McCrae, R. R., \& Costa, P. T., Jr. (2013). Introduction to the empirical and theoretical status of the five-factor model of personality traits. In T. A. Widiger \& P. T. Costa (Eds.), Personality disorders and the five-factor model of personality (3rd ed., pp. 15-27). Washington, DC: American Psychological Association. doi:10.1037/13939-002

Mishkevich, A. M., \& Shchebetenko, S. A. (2017). Psikhometrika russkoyazychnoi versii Big Five Inventory: novye svidetel'stva [Psychometrics of the Russian version of the Big Five Inventory: A new evidence] In A. L. Zhuravlev \& V. A. Kol'tsova (Eds.), Fundamental'nye i prikladnye issledovaniya sovremennoi psikhologii: rezul'taty i perspektivy razvitiya [Fundamental and applied studies in contemporary psychology: Results and prospects of development] (pp. 771-776). Moscow: Institute of Psychology of the RAS.

Shchebetenko, S. A. (2014). "The best man in the world": Attitudes toward personality traits. Psychology. Journal of the Higher School of Economics, 11(3), 129-148.

Shchebetenko, S. A. (2015). Reflexive characteristic adaptations within the Five-Factor Theory of personality framework. Psikhologicheskii Zhurnal, 36(6), 55-65. (in Russian)

Shchebetenko, S. (2017). Reflexive characteristic adaptations explain sex differences in the Big Five: But not in neuroticism. Personality and Individual Differences, 111, 153-156.

Shchebetenko, S. A., \& Tutikova, E. A. (2015). "The picture is good because openness to experience is good": The mediating role of attitudes toward personality traits in individual differences in painting preferences. Psychology. Journal of the Higher School of Economics, 12(4), 122-141. (in Russian)

Arina M. Mishkevich - senior lecturer, department of developmental psychology, Perm State University.

Research area: psychology of personality, social attitudes.

E-mail: ArinaMishkevich@ya.ru 